\title{
МЕДІА-РЕЛІГІЙНІСТЬ ЯК НОВА ФОРМА ПРОЯВУ РЕЛІГІЙНОЇ СВІДОМОСТІ: ПСИХОЛОГІЧНИЙ АНАЛІЗ ФЕНОМЕНУ
}

\author{
Коструба Наталія \\ Волинський національний університет імені Лесі Українки, \\ м. Луцьк, Україна, \\ chmil.nata@ukr.net \\ https://orcid.org/0000-0002-3852-4729
}

Мета. У статті здійснено теоретичний аналіз психологічних особливостей медіа-релігійності як нової форми прояву релігійної свідомості.

Методи. Для реалізації мети дослідження були використані методи теоретичного наукового пошуку: аналіз, синтез, узагальнення, психологічне моделювання.

Результати. Аналіз українських та закордонних праць щодо психологічних аспектів медіа-релігійності дозволив окреслити особливості цього феномену, визначити його структурні компоненти. Науковці описують загальні риси медіа-релігійної картини світу, серед яких масштабність, гіпер символічність, орієнтація на сьогодення, емоційна насиченість повідомлень. Релігія у медіа виконує просвітницьку, комунікативну, терапевтичну та популяризаційну (рекламну) функції. Медіа-релігійність - це нова форма релігійної діяльності та функціонування релігійної свідомості, яка виникла завдяки розвитку масової культури та засобів масової інформації. Така релігійність особистості має мережеві принципи комунікації, розмиває кордони між сакральним, ритуальним і секулярним, світським, змінює релігійну ідентичність особистості. Медіа-релігійність дає можливість брати участь у онлайн службах із будь якої точки світу i, таким чином, дає можливість обрати релігійний напрямок, не приіязуючись до певної території чи країни. Медіарелігійність має трьох компонентну структуру: когнітивний (проявляється як раціональний чи ірраціональний), емоційно-мотиваційний (орієнтація на зовнішні чи внутрішні цінності) та поведінковий (діяльність релігійна активна чи пасивна).

Висновки. Загалом, можна підсумувати, що медіа-релігійність є закономірним проявом процесу переходу релігії у інформаціне суспільство. Перспективи подальшого вивчення проблеми вбачаємо iз розробкою стандартизованого опитувальника дослідження особливостей медіа-релігійності особистості.

ISSN 2308-3743 (Online), ISSN 2227-1376 (Print)

(C) Коструба Н., 2021. Ця стаття відкритого доступу на умовах CC BY-NC 4.0 
Ключові слова: релігійність, медіа-релігійність, цифрова релігія, онлайнрелігія, психологія медіа, психологія релігії.

Kostruba Natalia. Media religiosity as a new form of manifestation of religious consciousness: a psychological analysis of the phenomenon.

Purpose. The aim of the article is theoretical analysis of the psychological features of media religiosity as a new form of manifestation of religious consciousness.

Methods. To realize the purpose of the study, we used the methods of theoretical scientific research: analysis, synthesis, generalization, psychological modeling.

Results. The paper show that general features of the media-religious picture of the world, including scale, hyper-symbolism, focus on the present, emotional saturation of messages. Religion in the media performs educational, communicative, therapeutic and promotional (advertising) functions. Media religiosity is a new form of religious activity and the functioning of religious consciousness, which arose due to the development of mass culture and mass media. Features of this type of religiosity: network principles of communication, blurs the boundaries between sacred, ritual and secular, secular, changes the individual's religious identity. Media religiosity makes it possible to participate in online services from anywhere in the world and thus allows you to choose a religious direction without being attached to a particular territory or country. Media-religiosity consists of three components: cognitive (manifested as rational or irrational), emotional-motivational (focus on external or internal values) and behavioral (religious activity is active or passive).

Conclusions. In general, we can conclude that media religiosity is a natural manifestation of the process of religion integration into the information society. We see prospects for further research the problem with the development of a standardized questionnaire to study the features of media religiosity.

Keywords: religiosity, media religiosity, digital religion, online religion, media psychology, psychology of religion.

Коструба Наталья. Медиа-религиозность как новая форма проявления религиозного сознания: психологический анализ феномена.

Цель. В статье осуществлен теоретический анализ психологических особенностей медиа-религиозности как новой формы проявления религиозного сознания.

Методы. Для реализации цели исследования были использованы методы теоретического научного поиска: анализ, синтез, обобщение, психологическое моделирование.

Результаты. Анализ украинских и зарубежных работ по психологическим аспектам медиа-религиозности позволил определить особенности этого феномена, его структурные компоненты. Ученые описывают общие черты медиа-религиозной картины мира, среди них масштабность, гипер символичность, ориентация на настоящее, эмоциональная насыщенность 
сообщений. Религия в медиа выполняет просветительскую, коммуникативную, терапевтическую и популяризационную (рекламную) функции. Медиарелигиозность - это новая форма религиозной деятельности и функционирования религиозного сознания, которая возникла благодаря развитию массовой культуры и средств массовой информации. Такая религиозность личности имеет сетевые принципы коммуникации, размывает границы между сакральным, ритуальным и секулярным, светским, меняет религиозную идентичность личности. Медиа-религиозность дает возможность участвовать в онлайн службах с любой точки мира и, таким образом, дает возможность выбрать религиозное направление, а не прииязуючись к определенной территории или страны. Медиа-религиозность имеет трех компонентную структуру: когнитивный (проявляется как рациональный или иррациональный), эмоционально-мотивационный (ориентация на внешние или внутренние ценности) и поведенческий (деятельность религиозная активная или пассивная).

Выводы. В общем, можно подытожить, что медиа-религиозность является закономерным проявлением процесса перехода религии в Информационный общество. Перспективы дальнейшего изучения проблемы видим разработкой стандартизированного опросника исследования особенностей медиарелигиозности личности.

Ключевые слова: религиозность, медиа-религиозность, цифровая религия, онлайн-религия, психология медиа, психология религии.

\section{Вступ.}

Діджиталізація перетворила інформаційний простір у важливу сферу соціального функціонування. Масова інтеграція особистостей та їхнього соціального життя у віртуальний світ пришвидшилась через світову пандемію Covid-19. Враховуючи нові умови, релігія освоює нові засоби комунікації, що і $є$ причиною суттєвих змін змісту та способу релігійного життя суспільства. Тепер через інформаційний простір людина формує релігійну свідомість та отримує певні релігійні уявлення (Дрей, 2013: 68). Важливу роль відіграє мас медіа у формуванні релігійної ідентичності (Berger, Ezzy, 2009). Засоби масової інформації наразі виконують багато культурних та соціальних функцій інституціоналізованих релігій та забезпечують духовне керівництво, моральну орієнтацію, ритуальні уривки та відчуття спільності та належності (Hjarvard, 2011). Науковці стверджують, що узгоджуватися 3 винятковою природою ЗМІ може тільки релігія, яка не є ні інституційним служінням, ні абсолютним особистим досвідом (Hosseini, 2008). Загалом, жанр медіа має 
глибокий вплив на репрезентацію релігії, що передбачає складну модель збільшення різноманітності тем та перспектив (Furseth, 2018).

3 розвитком віртуального світу багато релігійних груп застосовують такі технології, як Second Life, щоб створити досвід сповідування в Інтернеті, який пропонує інтерактивне поклоніння через аватари (наприклад, англіканський собор у Second Life). Зараз ми бачимо, що Інтернет стає інструментом поширення служіння церкви на Інтернет-простори. Наприклад, ми спостерігаємо зростання Інтернет-містечок у багатьох церквах, а веб-трансляція послуг через програми для iPhone та Facebook (наприклад, LifeChurch.tv) стає загальним явищем. Таким чином, замість того, щоб стати альтернативним соціальним простором, цифрові технології стають важливою платформою, яка розширює та змінює релігійну практику для маси людей (Campbell, 2013).

Питання діджиталізації релігії та зміни традиційних форм релігійності у ії психологічних аспектах вивчена недосконало. Явище для науки відносно нове, про що свідчить також відсутність одного визначеного терміну для окреслення особливостей нової релігійності. Саме тому, метою нашої статті - теоретичне вивчення психологічних особливостей медіа-релігійності як нової форми прояву релігійної свідомості.

Методи та процедура дослідження. Для реалізації мети дослідження були використані методи теоретичного наукового пошуку: аналіз, синтез, узагальнення, психологічне моделювання. Матеріалом для опрацювання стали наукові праці українських та закордонних науковців.

\section{Обговорення результатів.}

Появу нових форм релігії та релігійності, що виникли в сучасних (світських) суспільствах, передбачало багато науковців. Зокрема, Th. Luckmann стверджує про зміну ролі та функцій релігії в сучасному суспільстві і пропонує концепцію невидимої релігії (Luckmann, 1993). Про деінституціоналізацію релігії стверджує K. Gabriel (Gabriel, 1996). Парадигму «десекуляризації світу» пропонує P.L. Berger, який стверджує, що секуляризація на соціальному рівні не обов'язково пов'язана з секуляризацією на рівні індивідуальної свідомості. Автор говорить про появу нової форми суб'єктивної релігійності, яка є синкретичною, поєднує індивідуальну та інституціоналізовану релігію (Berger, 1999, 4). У межах огляду 
сучасної релігійності варто згадати про ще одну тенденцію у світі «бути духовним, але не релігійним» (Taylor, 2007: 535), бути «віруючим взагалі», але не належати до будь якої конкретної релігійної традиції (Рыжов, 2006: 120).

Сучасні форми прояву релігії Н. Knoblauch називає популярною релігією, підкреслюючи масову поширеність, а також «слід» релігії в політичних процесах, культурній ідентичності та цінностях (Knoblauch, 2009). S. Zviadadze описує трансформацію форм релігійності (Zviadadze, 2014). Ці нові форми описують різними поняттями «віртуальна релігійність» (Radde-Antweiler, 2008), «релігійність опосередкована технологіями» (Townsend, 2020), «медіарелігійність» (Рыжов, 2006), «цифрова релігія» (Campbell, 2013) тощо.

Д. М. Кошлаков стверджує, що у зв'язку 3 подальшим становленням і розвитком масової культури, можливість появи власне релігійних почуттів проблемна, але можлива. Автор виокремлює ряд особливостей сучасної релігійності (секуляризація релігійного i сакралізація світського, симуляція релігійності, детериторіалізація релігії, ідейний концептуальний плюралізм і еклектичність, мережеві принципи організації і комунікації, глобалізаційні тенденції і т.п.) (Кошлаков, 2009).

У контексті масової культури розглядає медіа-релігійність українська дослідниця М.С. Петрушевич. Авторка стверджує, що «телебачення у руслі релігійної комунікації фактично розмиває кордони між оригінальною релігійною комунікацією та іiі відображенням, копією та сприяє створенню медіа-релігійності» (Петрушевич, 2018: 288).

Аналіз медіа-релігійних продуктів на предмет формування особливої картини світу за критеріями В.С. Жидкова і К.Б. Соколова (Жидков, Соколов, 2003) здійснила Е. В. Царёва. Авторка описує загальні риси медіа-релігійної картини світу; масштабність, гіпер символічність, орієнтація на сьогодення, емоційна насиченість повідомлень. В цілому, для медіа-релігійності характерне пасивне сприйняття життя, навіть при активному медіа споживацтві. В медіарелігійних продуктах рефлексія практично відсутня і може бути замінена прихованою пропагандою тієї чи іншої концепції. Зазвичай, матеріали, транслюють надзвичайно пластичну, конформну картину світу i сприймаються споживачами найчастіше через екран 
телевізора, монітора або мобільного пристрою. Таким чином вся картина світу грунтується на візуальних образах (Царёва, 2014).

Вчені з Фінляндії та Великобританії шляхом контент аналізу вивчали твіти звернені до Бога на предмет їхньої релігійності. Дослідники стверджують, що соціальні медіа як частина нинішнього цифрового спілкування та засоби масової інформації поміж інших виконують і релігійні функції. Твіттер теж функціонує як засіб для спілкування релігійних ідей та питань з іншими користувачами, i, що цікаво, також використовується для спілкування 3 трансцендентним Богом (Holmberg, Bastubacka, Thelwall, 2016).

Важливість надання віртуальних церковних послуг у часи пандемії Covid-19 підкреслюють вчені J. R. Bryson, L. Andres, A. Davies (Bryson, Andres, Davies, 2020). Науковці також розглядають взаємозв'язок між новими медіа-технологіями та релігійним маркетингом, а також аналізують, які релігії застосовують проактивні та агресивні стратегії ділового маркетингу (Chen, 2011). Таким чином, релігія у медіа виконує не лише просвітницьку та комунікативну, але й терапевтичну та популяризаційну (рекламну).

Деякі науковці розглядають поняття медіа-релігійності як негативне явище, як грубу підробку традиційної релігійності (Рыжов, 2006; Царёва, 2014; Benedikter, 2020). Проте ми іï розглядаємо як сучасну форму релігійності, породжену трансформацією сучасного світу і збільшенням ролі медіа телебачення, інтернету, соціальних мереж тощо. Такої ж думки дотримується V. Bhatia i переконує, що віртуальність принципово сприяє життєздатності священного об'єкта в цифровому індуїзмі (Bhatia, 2020).

Медіа-релігійність ми розглядаємо як нову форму вираження релігійної діяльності, яка виникла завдяки розвитку масової культури. Медіарелігійність може реалізовуватися активно, шляхом співтворення релігії у медіа та інтернет-середовищі (найбільш притаманне так званим неорелігіям), або пасивно, через сприйняття існуючих норм, традицій, які реалізуються у релігійних 3MI, додатках, онлайн трансляціях богослужінь (більш притаманне канонічним релігіям) (Коструба, 2020).

Релігійність особистості часто розглядають через призму іiі структурних компонентів, особливо коли потрібно зробити емпіричну верифікацію цього поняття (Пруцкова, 2012). Оскільки ми не розмежовуємо традиційне розуміння релігійності особистості з іiі 
новою формою, то пропонуємо розглядати особливості медіарелігійності через класичну у психології трьох компонентну структуру: когнітивний, емоційно-мотиваційний та поведінковий компоненти (Рис.1).

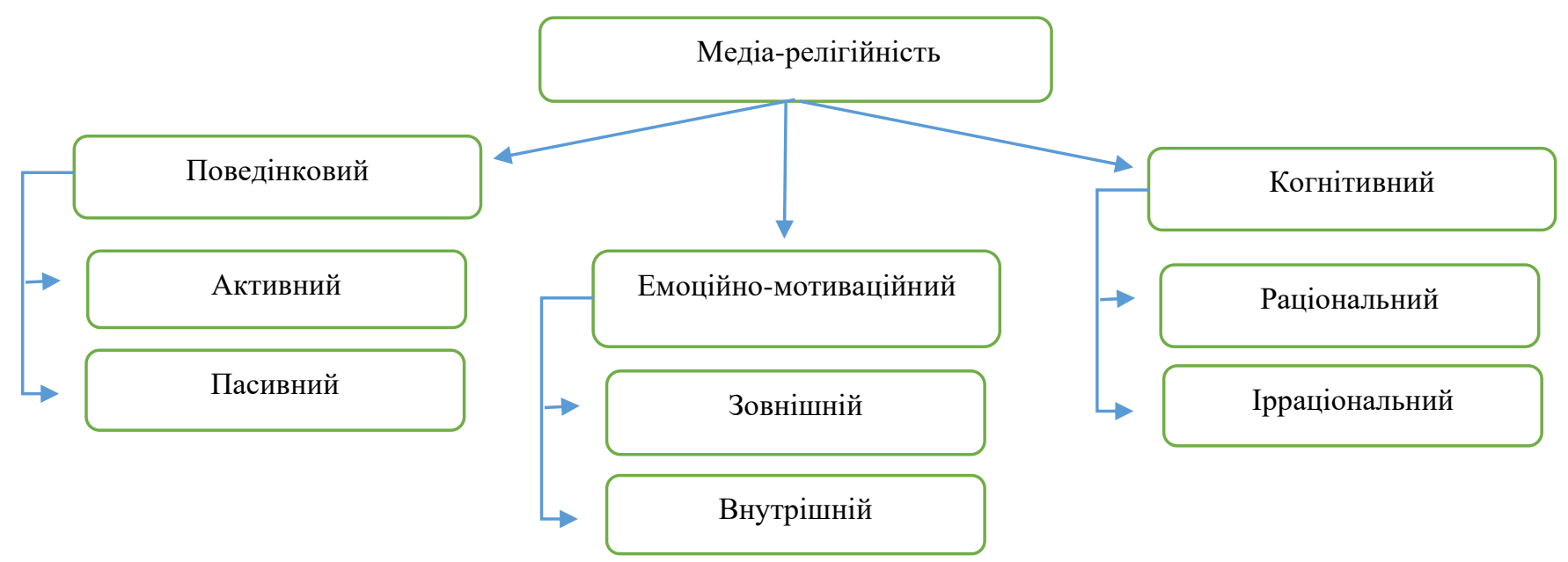

\section{Рис.1. Структура медіа-релігійності особистості}

Когнітивний компонент медіа-релігійності ми розглядаємо у континуумі раціональності-ірраціональності. Раціональна медіарелігійність стосується оцінки релігії з точки зору розуму, людина обгрунтовано обирає певний релігійний напрям шляхом аналітики для задоволення своїх релігійних потреб. Так на практиці це може проявлятися у підписках на релігійні ресурси новин, соціальні мережі, членство в інтернет-релігійних спільнотах тощо. Ірраціональна медіа-релігійність орієнтована на емоційне сприйняття світу та грунтується на вірі у містичні релігійні аспекти (чудеса зцілення, існування потойбічних сил, ангелів, демонів тощо). Проявляється така релігійність через поширення інформації про надприродні події, перегляд онлайн-трансляцій та відеозаписів релігійного змісту чи церковних служб для того, щоб відчути емоції та атмосферу.

Емоційно-мотиваційний компонент медіа-релігійності пропонуємо розглядати через діаду внутрішньої i зовнішньої орієнтації, запропонованої Г. Олпортом (Allport, 1968). Так, зовнішньо орієнтована медіа-релігійність спрямована на зовнішні, інструментальні цінності. Може проявлятися у виборі релігійної спільноти для задоволення не лише релігійних потреб, але й потреб афіляції, спілкування, фінансового достатку тощо. На практиці людина демонструє свою релігійність у соціальних мережах шляхом поширення відповідного контенту, публікує власні фото релігійних 
святкувань тощо. Внутрішньо орієнтована медіа-релігійність спрямована на духовне життя людини, на глибоке почуття віри та бажання служити Богу i церкві. Проявляється така орієнтація у спілкуванні про сенс життя, релігійні роздуми, об'єднання 3 однодумцями, благодійництво що може бути опосередковане засобами масової інформації.

Поведінковий компонент медіа-релігійності ми пропонуємо розглядати через призму активності-пасивності. Так, активна медіарелігійність передбачає активну публікацію і поширення світлин і дописів щодо власного релігійного досвіду, участі у релігійних обрядах, спілкування на релігійні теми у інтернеті через блоги, соціальні мережі. Пасивна медіа-релігійність проявляється у підписках на сайти і соціальні мережі на релігійні новини та іншу дотичну тематику.

Висновки та перспективи. Трансформація суспільних процесів у зв'язку із діджиталізацією усіх сфер життя змінила і спосіб сповідування релігії. Для залучення молодого покоління до релігії та віри більшість церков в Україні та світі розширили свою діяльність у засобах масової інформації. Усі ці події стали причиною для виникнення нової форми релігійності і єдиного поняття для означення цього феномену у науковій спільноті наразі немає. Ми пропонуємо термін медіа-релігійність особистості.

Аналіз українських та закордонних праць щодо психологічних аспектів медіа-релігійності дозволив окреслити особливості цього феномену, визначити його структурні компоненти. Медіа-релігійність - це нова форма релігійної діяльності, яка виникла завдяки розвитку масової культури та засобів масової інформації. Така релігійність особистості має мережеві принципи комунікації, розмиває кордони між сакральним, ритуальним i секулярним, світським. Медіарелігійність не прив'язує до певної території чи храму, дає можливість брати участь у онлайн службах із будь якої точки світу. Медіа-релігійність має трьох компонентну структуру: когнітивний (проявляється як раціональний чи ірраціональний), емоційномотиваційний (орієнтація на зовнішні чи внутрішні цінності) та поведінковий (діяльність релігійна активна чи пасивна).

Загалом, можна підсумувати, що медіа-релігійність $є$ закономірним проявом процесу переходу релігії у інформаціне суспільство. Дослідження цього феномену вбачаємо дуже актуальним 
i своєчасним, тому перспективи подальшого вивчення проблеми будуть пов'язані із розробкою стандартизованого опитувальника виявлення ступеню прояву медіа-релігійності у структурі релігійності особистості.

\section{Література}

1. Дрей, К. В. (2013). Трансформація релігійної свідомості у сучасному інформаційному суспільстві. Наука. Релігія. Суспільство, 3, 64-69.

2. Жидков, В.С.; Соколов, К.Б. (2003). Искусство и картина мира. СПб: Алетейя.

3. Коструба, Н.С. (2020). Психологічний аналіз феномену медіарелігійності. Особистість $і$ суспільство: методологія та практика сучасної психології : матеріали VII Міжнар. наук.-практ. інтернет-конф. = Abstract VII International Scientific \& Practical Internet Conference. (c. 51-53). Луцьк : ПП Іванюк В. П.

4. Кошлаков, Д.М. (2009). Особенности современной религиозности. Сибирь на перекрестье мировых религий: материаль четвертой межрегион. науч.-практ. конф., посвящ. памяти выдающегося ученого и педагога, специилиста по библеистике, проф. НГУ М.И.Рижского. (с. 35-39). Новосибирск: НГУ.

5. Петрушкевич, М.С. (2018). Релігійна комунікація у контексті масової культури. Острог: Видавництво Національного університету "Острозька академія".

6. Пруцкова, Е. (2012). Операционализация понятия «Религиозность» в эмпирических исследованиях. Государство, религия, цеекковь в России и за рубежсм, 2 (30), 268-293.

7. Рыжов, Ю.В. (2006). Медиарелигиозность: основа будущей религии? Человек, 4, 119-126.

8. Царёва, Е. В. (2014). Медиарелигиозность и речевая агрессия. Молодежь и наука: сборник материалов Х Юбилейной Всероссийской научнотехнической конференции студентов, аспирантов $u$ молодых ученых $c$ международным участием, посвященной 80-летию образования. Красноярского края. Красноярск: Сибирский федеральный ун-т.

9. Allport, G. W. (1968). The person in psychology: selected essays. Boston: Beacon press.

10. Benedikter, R. (2020). Technology: the new God? Religion in the Age of Digitalization. London, UK: Routledge.

11. Berger, P.L. 1999, 'The Desecularization of the World: A Global Overview'. The Desecularization of the World: Resurgent Religion and World Politics. (pp. 118). Washington: Grand Rapids.

12. Berger, H., \& Ezzy, D. (2009). Mass Media and Religious Identity: A Case Study of Young Witches. Journal for the Scientific Study of Religion, 48(3), 501-514. 
13. Bhatia, V. (2020). Shani on the Web: Virality and Vitality in Digital Popular Hinduism. Religions, 11, 456. DOI: https://doi.org/10.3390/rel11090456

14. Bryson, J. R., Andres, L., \& Davies, A. (2020). COVID-19, Virtual Church Services and a New Temporary Geography of Home. Journal of economic and social geography, 111(3), 360-372. DOI: https://doi.org/10.1111/tesg.12436

15. Campbell, H. A. (2013). Introduction: The Rise of the Study of Digital Religion. Digital Religion. Understanding Religious Practice in New Media Worlds (pp. 1-21). London, UK: Routledge.

16. Chen, Ch. H. (2011). Marketing Religion Online: The LDS Church's SEO Efforts. Journal of Media and Religion, 10:4, 185-205. DOI: https://doi.org/10.1080/15348423.2011.625265

17. Furseth, I. (eds). (2018). Religious Complexity in the Public Sphere. Palgrave Studies in Religion, Politics, and Policy. Palgrave Macmillan, Cham. DOI: https://doi.org/10.1007/978-3-319-55678-9_5

18. Gabriel, K (1996). Religiöse Individualisierung oder Säkularisierung. Biographie und Gruppe als Bezugspunkte moderner Religiosität. Gütersloh: Kaiser Gütersloher Verl. Haus.

19. Hjarvard, S. (2011). The mediatisation of religion: Theorising religion, media and social change. Culture and Religion, 12:2, 119-135. DOI: https://doi.org/10.1080/14755610.2011.579719

20. Holmberg, K., Bastubacka, J., \& Thelwall, M. (2016). “@God please open your fridge!" Twitter messages to @God in content analysis: Hopes, humor, spirituality, and profanities. Journal of Religion, Media and Digital Culture, 5(2), 339-355. doi: https://doi.org/10.1163/21659214-90000085

21. Hosseini, S. H. (2008). Religion and Media, Religious Media, or Media Religion: Theoretical Studies. Journal of Media and Religion, 7:1-2, 56-69, DOI: https://doi.org/10.1080/15348420701838350

22. Knoblauch, H. (2009). Populäre Religion. Auf dem Weg in eine spirituelle Gesellschaft? Frankfurt am Main: Campus.

23. Luckmann, Th.(1993). Die unsichtbare Religion. Frankfurt am Main: Suhrkamp.

24. Radde-Antweiler, K. (2008). Virtual Religion. An Approach to a Religious and Ritual Topography of Second Life. Online - Heidelberg Journal of Religions on the Internet, 3, 174-211.

25. Taylor, Ch. (2007). A Secular Age. Massachusetts: Cambridge.

26. Townsend, A. (2020). Technology-mediated religiosity of elderly in Covid19 social isolation. Media Psychology (Virtual) Symposium 2020. DOI: https://doi.org/10.13140/RG.2.2.24844.33927

27. Zviadadze, S. (2014). I 'like' my Patriarch. Religion on Facebook. New Forms of Religiosity in Contemporary Georgia. Online - Heidelberg Journal of Religions on the Internet, 6, 164-194. DOI: https://doi.org/10.11588/rel.2014.0.17365 


\section{References}

1. Drei, K. V. (2013). Transformatsiia relihiinoi svidomosti u suchasnomu informatsiinomu suspilstvi [Transformation of religious consciousness in the modern information society]. Nauka. Relihiia. Suspilstvo - Science. Religion. Society, 3, 6469. [in Ukrainian].

2. Zhidkov, V.S.; Sokolov, K.B. (2003). Iskusstvo i kartina mira [Art and the picture of the world]. SPb: Aleteyya. [in Russian].

3. Kostruba, N.S. (2020). Psykholohichnyi analiz fenomenu mediarelihiinosti [Psychological analysis of the phenomenon of media religiosity]. Osobystist $i$ suspilstvo: metodolohiia ta praktyka suchasnoi psykholohii : materialy VII Mizhnar. nauk.-prakt. internet-konf. - Abstract VII International Scientific \& Practical Internet Conference. (pp. 51-53). Lutsk : PP Ivaniuk V. P. [in Ukrainian].

4. Koshlakov, D.M. (2009). Osobennosti sovremennoy religioznosti [Features of modern religiosity]. Sibir na perekreste mirovyih religiy: materialyi chetvertoy mezhregion. nauch.-prakt. konf., posvyasch. pamyati vyidayuschegosya uchenogo $i$ pedagoga, spetsialista po bibleistike, prof. NGU M.I.Rizhskogo - Siberia at the crossroads of world religions: materials of the fourth interregion. scientific-practical conf., dedicated. memory of an outstanding scientist and teacher, specialist in biblical studies, prof. NSU M.I. Rizhsky. (s. 35-39). Novosibirsk: NGU. [in Russian].

5. Petrushkevych, M.S. (2018). Relihiina komunikatsiia u konteksti masovoi kultury [Religious communication in the context of mass culture]. Ostroh: Vydavnytstvo Natsionalnoho universytetu "Ostrozka akademiia". [in Ukrainian].

6. Prutskova, E. (2012). Operatsionalizatsiya ponyatiya «Religioznost» v empiricheskih issledovaniyah [Operationalization of the concept of "Religiosity" in empirical research]. Gosudarstvo, religiya, tserkov v Rossii $i$ za rubezhom - State, religion, church in Russia and abroad, 2 (30), 268-293. [in Russian].

7. Ryizhov, Yu.V. (2006). Mediareligioznost: osnova buduschey religii? [Media Religiousness: The Basis of the Future Religion?]. Chelovek - Man, 4, 119126. [in Russian].

8. Tsaryova, E. V. (2014). Mediareligioznost i rechevaya agressiya [Media religiosity and speech aggression]. Molodezh $i$ nauka: sbornik materialov $H$ Yubileynoy Vserossiyskoy nauchno-tehnicheskoy konferentsii studentov, aspirantov $i$ molodyih uchenyih $s$ mezhdunarodnyim uchastiem, posvyaschennoy 80-letiyu obrazovaniya - Youth and science: a collection of materials of the X Anniversary AllRussian scientific and technical conference of students, graduate students and young scientists with international participation, dedicated to the 80th anniversary of education. Krasnoyarsk: Sibirskiy federalnyiy un-t. [in Russian].

9. Allport, G. W. (1968). The person in psychology: selected essays. Boston: Beacon press.

10. Benedikter, R. (2020). Technology: the new God? Religion in the Age of Digitalization. London, UK: Routledge. 
11. Berger, P.L. 1999, 'The Desecularization of the World: A Global Overview'. The Desecularization of the World: Resurgent Religion and World Politics. (pp. 118). Washington: Grand Rapids.

12. Berger, H., \& Ezzy, D. (2009). Mass Media and Religious Identity: A Case Study of Young Witches. Journal for the Scientific Study of Religion, 48(3), 501-514.

13. Bhatia, V. (2020). Shani on the Web: Virality and Vitality in Digital Popular Hinduism. Religions, 11, 456. DOI: https://doi.org/10.3390/rel11090456

14. Bryson, J. R., Andres, L., \& Davies, A. (2020). COVID-19, Virtual Church Services and a New Temporary Geography of Home. Journal of economic and social geography, 111(3), 360-372. DOI: https://doi.org/10.1111/tesg.12436

15. Campbell, H. A. (2013). Introduction: The Rise of the Study of Digital Religion. Digital Religion. Understanding Religious Practice in New Media Worlds (pp. 1-21). London, UK: Routledge.

16. Chen, Ch. H. (2011). Marketing Religion Online: The LDS Church's SEO Efforts. Journal of Media and Religion, 10:4, 185-205. DOI: https://doi.org/10.1080/15348423.2011.625265

17. Furseth, I. (eds). (2018). Religious Complexity in the Public Sphere. Palgrave Studies in Religion, Politics, and Policy. Palgrave Macmillan, Cham. DOI: https://doi.org/10.1007/978-3-319-55678-9_5

18. Gabriel, K (1996). Religiöse Individualisierung oder Säkularisierung. Biographie und Gruppe als Bezugspunkte moderner Religiosität. Gütersloh: Kaiser Gütersloher Verl. Haus.

19. Hjarvard, S. (2011). The mediatisation of religion: Theorising religion, media and social change. Culture and Religion, 12:2, 119-135. DOI: https://doi.org/10.1080/14755610.2011.579719

20. Holmberg, K., Bastubacka, J., \& Thelwall, M. (2016). “@God please open your fridge!" Twitter messages to @God in content analysis: Hopes, humor, spirituality, and profanities. Journal of Religion, Media and Digital Culture, 5(2), 339-355. doi: https://doi.org/10.1163/21659214-90000085

21. Hosseini, S. H. (2008). Religion and Media, Religious Media, or Media Religion: Theoretical Studies. Journal of Media and Religion, 7:1-2, 56-69, DOI: https://doi.org/10.1080/15348420701838350

22. Knoblauch, H. (2009). Populäre Religion. Auf dem Weg in eine spirituelle Gesellschaft? Frankfurt am Main: Campus.

23. Luckmann, Th.(1993). Die unsichtbare Religion. Frankfurt am Main: Suhrkamp. 
24. Radde-Antweiler, K. (2008). Virtual Religion. An Approach to a Religious and Ritual Topography of Second Life. Online - Heidelberg Journal of Religions on the Internet, 3, 174-211.

25. Taylor, Ch. (2007). A Secular Age. Massachusetts: Cambridge.

26. Townsend, A. (2020). Technology-mediated religiosity of elderly in Covid19 social isolation. Media Psychology (Virtual) Symposium 2020. DOI: https://doi.org/10.13140/RG.2.2.24844.33927

27. Zviadadze, S. (2014). I 'like' my Patriarch. Religion on Facebook. New Forms of Religiosity in Contemporary Georgia. Online - Heidelberg Journal of Religions on the Internet, 6, 164-194. DOI: https://doi.org/10.11588/rel.2014.0.17365

Received: 22.01.2021

Accepted: 06.02.2021 